\title{
The Effect of Low Concentrations of Bedload on the Erosion Pattern and the Structural Strength of Rigid Force Mains
}

\author{
Hillel Rubin ${ }^{1, *}$, Dmitry Tokarev ${ }^{1}$ and Holger Schüttrumpf ${ }^{2}$ \\ ${ }^{I}$ Faculty of Civil and Environmental Engineering, Technion - Israel Institute of Technology, Haifa 32000, Israel \\ ${ }^{2}$ Institute of Hydraulic Engineering and Water Resources Management, RWTH Aachen University, Aachen, Germany
}

\begin{abstract}
This manuscript concerns the decrease of the structural strength and possible collapse of force (pressure) mains due to bedload erosion (abrasion), caused by low concentrations of hard solid particles transported with the sanitary sewage. Such a phenomenon may probably occur in combined sanitary systems (CSS), but it has also been observed in force mains delivering domestic sewage, due to occasional penetration of hard solid particles into the sanitary sewerage system. Force mains are usually subject to stresses originating from the internal pressure combined with those of the external load. For the design of such pipelines, Schlick's formula is usually applied. The present study applies Schlick's formula to represent the pipe failure curve. Then by properly introducing safety factors into Schlicks' formula the study defines service curves of the pipe. Each service curve is associated with a particular value of the pipe construction safety factor. In the next step by applying the concept of service curves the study hypothesizes the extension of Schlick's formula for possible calculation of the decrease of the pipe safety factor due to the presence of the invert groove. Calculations are made by using the ANSYS code, and the numerical results are applied to evaluate a particular case history of an asbestoscement (AC) force main collapse.
\end{abstract}

Keywords: Force main failure; pipe abrasion; pipe collapse; pipe rapture; pipe crushing; bedload erosion; pipe structural strength.

\section{INTRODUCTION}

This study has originated from a case history of asbestoscement (AC) pressure main (force main) collapse that took place in Tel-Aviv area, Israel. At the invert of the collapsed pipe a $40 \mathrm{~mm}$ wide and $20 \mathrm{~mm}$ deep groove has been found. This groove has been the result of many years of bedload erosion caused by low concentrations of hard solid particles (sand and gravels) transported with the domestic wastewater delivered through that main. The force main has been designed to deliver domestic sewage, but usually during the winter time some quantities of surface runoff with hard sediments penetrated into the sanitary sewerage system. Further, even in summer time some quantities of hard solid particles were supplied into the sewerage system by improper washing facilities in various places. Manufacturing AC products like AC pipes has been banned in most developed countries (e.g., [1, 2]) including Israel. However, such pipes are still at work for conveying water and wastewater in many places while providing good service. As force mains or gravity sewers, they are often subject to external load combined with internal pressure. Further, the information of this study is relevant to most types of rigid pipes made of materials of low and medium resistance to abrasion, like concrete. The force main in Tel-Aviv area collapsed on January 28, 2003, after about 30 years of completing its

*Address correspondence to the author at the Faculty of Civil and Environmental Engineering, Technion - Israel Institute of Technology, Haifa 32000, Israel; Tel: +(972) 4-829-2306; Fax: +(972) 4-822-8898;

E-mail: hrubin@technion.ac.il installation. During the performance of this study, the authors have collected some details about another case history of interest and relevance to this study, which has taken place in Vancouver, British Columbia, Canada, where the force main has been made of prestressed concrete comprising part of the combined sanitary system (CSS). In such a sewerage system a single sewer network is used for conveying surface runoff and wastewater [3]. Therefore, every rain storm leads to flow of surface run-off with hard solid particles mixed with the raw wastewater through the force mains. In this case the force main has been subject to various events of failure starting in 1996, following approximately twenty years of proper service. However, it should be noted that before arriving at the pumping station the wastewater is transferred through settling tanks, where most quantities of the hard solid particles settle. Therefore, the concentration of hard solid particles is particularly low in the wastewater flowing through force mains. Later, we provide some quantitative information about this issue.

In both cases mentioned in preceding paragraphs, the low concentration of hard solid particles transported with the wastewater has created grooves of a particular prismatic shape at the pipe invert, as shown in Fig. (1). The groove developed at the pipe invert has decreased the structural strength of the pipe. In pipes made of reinforced or prestressed concrete the groove at the pipe invert may allow direct contact between the steel bars and wires and the flowing wastewater. This contact may lead to intensive corrosion of the steel bars and wires leading to fractures at the concrete pipe wall. According to our literature survey, the latter 
phenomenon may also take place in reinforced and prestressed concrete pipes even if the groove of abrasion has not developed (e.g., [4, 5]) probably in cases of improper production of such pipes.

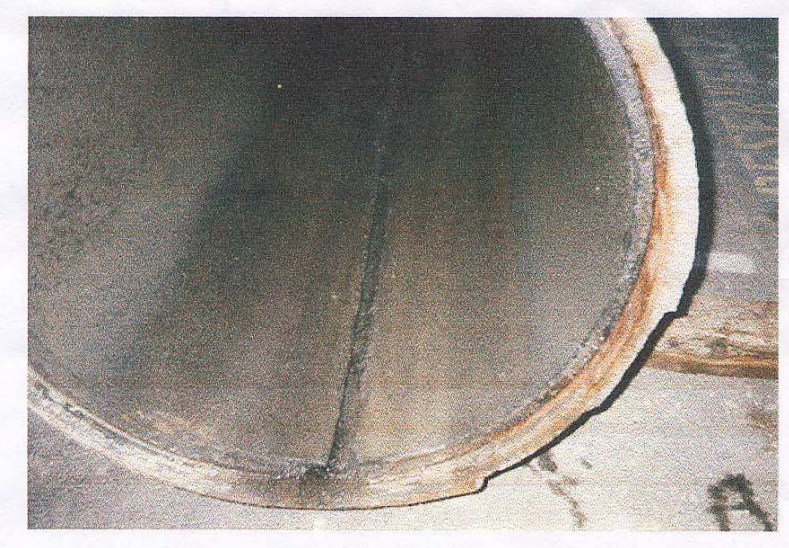

Fig. (1). The groove developed at the invert of the pressure main in Vancouver [6].

\section{DETAILS OF RELEVANT CASE HISTORIES}

The force main in Tel-Aviv area is made of AC pipes whose inner diameter is $1,250 \mathrm{~mm}$. It should be noted that presently International Standards are applied to Israel, and such a diameter of AC pipe is not specified by the International Standards, like ISO-160 and ISO-881 (a list of standards cited by this paper is given in the Appendix). However, the force main was installed in Tel-Aviv area in 1973, when ISO was not a formal standard of Israel. The force main has incorporated several sections of different classes of AC pressure pipes symbolized by the letters $\mathrm{A}-\mathrm{E}$, which refer to nominal pressures $6-24$ bar $(0.6-2.4 \mathrm{MPa})$, respectively. The choice of the different pipe classes for the pipe sections has been made by calculating the external load (backfill, content load, self-weight and live load) and the internal pressure. The force main has been installed on an ascending topography with its lowest level located at the wastewater pumping station, where the pressure is up to 4 bar $(0.4 \mathrm{MPa})$. The collapsed pipe was of class B (of wall thickness $70 \mathrm{~mm}$ ), and the calculated pressure in the pipe during its collapse was around 3.7 bar $(0.37 \mathrm{MPa})$. The initial fracture, which led to the pipe wall failure, took place at the groove that has been identified at the pipe invert. The groove, which is schematically shown in Fig. (2) had a prismatic shape of maximum depth of around $20 \mathrm{~mm}$, and maximum width of around $40 \mathrm{~mm}$. Its cross section could schematically be described as trapezoidal or semi-circular. The pipeline survey has indicated the groove has been extended along a significant length of the pipeline. On the other hand close to elbow connections, where scheduled maintenance surveys could be made through observation openings, the groove has not developed. After the pipe collapse, it became clear that at elbow connections, due to local secondary wastewater currents, the groove could not develop.

Past events of heavy rain storms have led to storm runoff with hard solid particles, like sand and gravel, penetrat- ing into the sewerage system and mixed with the raw sewage. However, most quantities of hard solid particles have settled within traps and settling tanks properly designed and constructed at the upstream side of the wastewater pumping station. According to the range of flow velocities $(1.36 \mathrm{~m} / \mathrm{s}-$ $2.1 \mathrm{~m} / \mathrm{s}$ ) through the force main, it seems the remaining low concentrations of sand and small gravel particles moving as bedload have caused gradual development of the narrow and deep groove abrasion pattern at the invert of the force main.

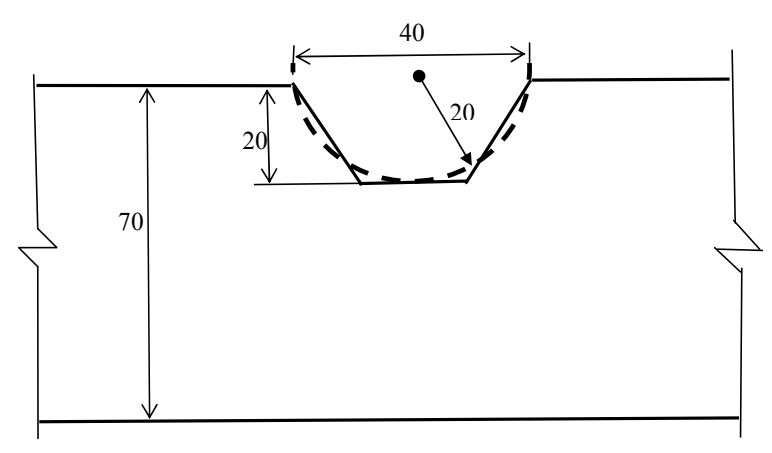

Fig. (2). Schematic descriptions of the force main invert groove in Tel-Aviv area (sizes are given in $\mathrm{mm}$ ).

The concentration of hard solid particles in the flowing wastewater has been calculated by applying several different sources of information:

1) According to a table of quantities of refuse arriving at the upstream side of the biological reactors comprising the wastewater treatment facility, during March 2005 - January 2006 (306 days) the total quantity of that refuse was $8,547,000 \mathrm{~kg}$. Around two thirds of this quantity was grit (material comprising of sand and gravel, which is saturated with water), namely $5,698,000 \mathrm{~kg}$. During that time period the total quantity of wastewater arriving at the wastewater treatment plant was $101,440,294 \mathrm{~m}^{3}$;

2) Everyday the quantities of grit settled at the upstream side of the biological reactors have been taken away from the wastewater treatment plant by containers incorporating around $18,000 \mathrm{~kg}$ of grit, and

3) In addition to the grit quantities reported above there are some quantities of solid hard particles comprising mainly of sand particles that have passed through the settling facilities and settled at the two biological reactors. After 10 years of operation of the biological reactors a total quantity of $5,000 \mathrm{~m}^{3}$ of saturated sand and gravels has been taken out of one of these reactors.

We start with calculating the average density of the hard solid (sand and gravels) particles. The density of the grit, which is saturated with water, is around $2,000 \mathrm{~kg} / \mathrm{m}^{3}$. The porosity of the grit is around 0.4 , namely $40 \%$ of the grit incorporates water, whose density is $1,000 \mathrm{~kg} / \mathrm{m}^{3}$. Therefore, the obtained density of the hard solid particles (sand and gravels) is:

$\rho_{s}=\frac{2,000-0.4 \times 1,000}{0.6}=2,667 \mathrm{~kg} / \mathrm{m}^{3}$ 
where $\rho_{s}$ is the average density of hard solid particles. Applying this value and the information about the quantities of grit accumulated at the biological reactor during 10 years of operation, we obtain:

$m_{s b r}=\left(\frac{5,000 \times 2}{365 \times 10}\right) \times 0.6 \times 2,667=4,384 \mathrm{~kg} /$ day

where $m_{s b r}$ is the average total mass of hard solid particles (whose average density is around $2,667 \mathrm{~kg} / \mathrm{m}^{3}$ ), which is accumulated everyday at the biological reactor.

In the next step we apply the information about quantities of grit accumulated upstream of the biological reactors during March 2005 - January 2006 (306 days). Again considering the density of the saturated grit is $2,000 \mathrm{~kg} / \mathrm{m}^{3}$, and that of the solid particles is around $2,667 \mathrm{~kg} / \mathrm{m}^{3}$, we get:

$m_{\text {sur }}=\frac{5,698,000}{2,000 \times 306} \times 0.6 \times 2,667=14,899 \mathrm{~kg} /$ day

where $m_{\text {sur }}$ is the average total mass of hard solid particles accumulated everyday upstream of the biological reactor. During those 306 days the total quantity of wastewater arriving at the biological reactors was $101,440,294 \mathrm{~m}^{3}$, namely around $331,500 \mathrm{~m}^{3} /$ day. Therefore, the average concentration of hard solid particles transported through the pressure main has been:

$C_{s}=\frac{m_{s b r}+m_{s u r}}{Q_{d}}=\frac{4,400+14,900}{331,500}=0.058 \mathrm{~kg} / \mathrm{m}^{3}$

where $C_{s}$ is the average concentration of hard solid particles in the wastewater, $Q_{d}$ is the average total volume of wastewater arriving at the biological reactors during a single day.

In the next step we check the reliability of our calculations (which have indicated a very low average concentration of solid hard particles) by applying the information about the quantities of grit taken away from the settling basins located upstream of the biological reactors. This calculation comes to evaluate the result obtained in Equation (3):

$m_{\text {sur }}=\left(\frac{18,000}{2,000}\right) \times 0.6 \times 2,667=14,400 \mathrm{~kg} / \mathrm{m}^{3}$

This result is basically identical with that of Equation (3). The result of Equation (4) indicates very low average concentration of hard solid particles transported with the wastewater. However, probably there are some changes of $C_{s}$ during the day and in different seasons. The process of rigid pipe bedload erosion due to low concentrations of hard solid particles probably comprises a challenging topic of research. However, the focus and the objective of this study are concentrated on developing a simplified method of analysis for evaluating the effect of the groove, schematically shown in Fig. (3), on the rigid force main structural strength.

Our literature survey has not supplied information about the development of a groove as observed in Tel-Aviv area. However, personal meetings with various professionals and local city reports that we have gotten from Vancouver area $[3,6]$ have indicated the abrasion and development of a groove at the invert of force mains conveying low concentrations of hard solid particles transported with the wastewater is probably not rare. The force main in Vancouver was made of prestressed concrete, in which the flow velocity range was $1.42 \mathrm{~m} / \mathrm{s}-3.27 \mathrm{~m} / \mathrm{s}$, which has caused the pattern of groove bedload erosion at the pipe invert. In most cases of groove developing in reinforced and prestressed concrete pipes probably the effect of the groove on the pipe strength has been minor, but the groove has led to direct contact between the wastewater flowing in the pipe and the steel bars. This phenomenon could lead to corrosion and expansion of the steel bars and thereby causing fractures in the concrete pipe wall.

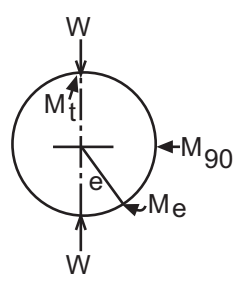

$$
\begin{aligned}
& M_{\theta}=W R\left(\frac{1}{\pi}-\frac{\sin \theta}{2}\right) \\
& M_{t}=M_{b}=\frac{W R}{\pi} \\
& M_{90}=W R\left(\frac{1}{\pi}-\frac{1}{2}\right)
\end{aligned}
$$

Fig. (3). Schematics of bending moment developed by two edge-loading [9].

\section{REQUIRED STRUCTURAL STRENGTH OF FORCE MAINS}

According to standards referring to pipe testing like, AWWA C-403, ASTM C-14, ASTM C-296, ASTM C-500, ASTM C-875, BS-486, ISO-160, ISO-881, ISO-2785, IS-27, IS-333 (see Appendix), the manufacturer of large diameter rigid pressure pipes should carry out the following two types of structural strength tests:

a) Resistance of the pipe to external load (crushing test), and

b) Resistance of the pipe to internal pressure (rupture test).

The crushing test provides information about the structural strength of the pipe to resist only the external load, namely backfill and live load. The rapture test provides information about the structural strength of the pipe to resist only the stresses imposed by its internal pressure.

Various standards, like ASTM C-418, ASTM C-779, ASTM C-944 (see Appendix) provide information about testing the resistance of concrete to abrasion. However, none of all these testing methods is relevant to the resistance of concrete pipes (or other types of rigid pipes) to abrasion by different types and concentrations of bedload and/or suspended load. Studies carried out by Gabriel [7] and by Jarvenkyla and Haavisto [8] have concerned the pipe wall abrasion. However, they have not described the formation of the groove at the pipe invert, as shown in Fig. (1), due to very low concentrations of hard sediments (solid particles) with the flowing water.

Standards of rigid pressure pipes do not require testing the structural resistance of the pipe to external load combined with internal pressure. However, force mains are usually subject to such a loading system. In following paragraphs we consider the proper approach for designing force mains subject to such a loading system.

At this stage we consider the effect of the external load on stresses developing at the pipe wall. Assuming the pipe 
wall is thin and making some minor approximations, the two-edge pipe crushing loading leads to distribution of bending moments per unit length at the pipe wall, as schematically shown in Fig. (3) [9]:

$$
\begin{aligned}
& M_{\theta}=W\left(\frac{D+d}{2}\right)\left(\frac{1}{\pi}-\frac{\sin \theta}{2}\right) \\
& M_{t}=M_{b}=\frac{W}{\pi}\left(\frac{D+d}{2}\right)=0.318 W\left(\frac{D+d}{2}\right) \\
& M_{90^{\circ}}=W\left(\frac{D+d}{2}\right)\left(\frac{1}{\pi}-\frac{1}{2}\right)
\end{aligned}
$$

where, $D$ is the internal diameter of the pipe, $d$ is the pipe wall thickness, $M$ is the bending moment per unit pipe length, $W$ is the applied two-edge external load per unit pipe length, $\theta$ is the angle between the radii of the pipe bottom and the point of the pipe wall at which $M_{\theta}$ is calculated, subscripts $t$ and $b$ refer to the top and bottom (namely, $\theta=180^{\circ}$, $0^{0}$ ) of the pipe, respectively. We may also represent the pipe cross section by a model of a clock, in which the top and bottom of the pipe cross section are the $12 \mathrm{hr}$ and $6 \mathrm{hr}$, respectively. Value of $\theta=90^{\circ}$ refers to $3 \mathrm{hr}$ and $9 \mathrm{hr}$ of the pipe cross section clock model. Equations (6) - (8) consider the pipe cross section as a thin ring model; therefore they incorporate an error of up to $5 \%$ for values of ratios of the pipe mean radius to its wall thickness larger than 7 . Tables of Roark's formulas [10] provide accurate expressions for the bending moments that develop in rings of all types subject to various types of loading. International standards, like ISO160 and ISO-881 (see Appendix) require calculating the pipe bending moment in the three-edge crushing test (which is an improved practical version of the two-edge loading) by using the formula:

$M_{\max }=n W\left(\frac{D+d}{2}\right)$

where $M_{\max }$ is the maximum value of the bending moment developed in the crushing three-edge loading test (namely, the bending moment at $12 \mathrm{hr}$ of the pipe cross section clock model), $n$ is a coefficient equal to 0.26 for pipes of up to 100 $\mathrm{mm}$ diameter and is 0.30 for diameters larger than this value.

The information and Equations $(6-9)$ given in the preceding paragraph indicate that under two-edge loading, bending moments of maximum absolute values develop at the top and bottom of the pipe cross section. At these points the bending moments are positive, namely the inner wall is subject to extension, and the outer wall is subject to compression. On the other hand at $\theta=90^{\circ}$ the bending moment obtains its maximum negative value, namely the inner wall is subject to compression, and the outer wall is subject to extension. Therefore, a crushing test, carried out by the three-edge apparatus, which is described by various standards, like ISO-881, ASTM C-500 (see Appendix), and texts issued by professional societies like, American Concrete Pipe Association [11] and American Water Works Association [12], as well as individuals, like Young and Trott [9] leads to the appearance of the first crack at the top of the pipe. If the rigid pipe is buried and subject to field service then the first crack due to external load is usually expected to appear at the bottom and/or top of the pipe.
According to international standards, like ISO-160 and ISO-881 (see Appendix), the maximum extension stress due to crushing should be calculated by using the formula:

$\sigma_{w \max }=k \frac{M_{\max }}{Z}$

where $k$ is a coefficient resulting from the curvature of the pipe, and $Z$ is the pipe wall modulus of resistance per unit length. Values of $k$ and $Z$ are given respectively by (e.g., [13]):

$k=\frac{3 D+5 d}{3 D+3 d}$

$Z=\frac{1}{6} d^{2}$

Applying Equations (9) - (12), the relationship between the critical external (three-edge) load, $W_{c r}$ and the critical stress due to such pipe loading, $\sigma_{w c r}$ is given by:

$W_{c r}=\sigma_{w c r}\left[\frac{d^{2}}{n(3 D+5 d)}\right]$

However, it should be noted that $W_{c r}$ is smaller than the critical external load, $W_{f c r}$ applied to the pipe under field service. The relationship between these two types of pipe critical external loads is given by:

$W_{f c r}=W_{c r} B_{f}$

where $B_{f}$ is the bedding factor, which depends on the pipe type of bedding. Values of $B_{f}$ are given by various guidebooks of different societies and associations (e.g., [11]).

If the pipe is subject to internal pressure then according to the thin ring assumption, the relationship between the critical pressure, $p_{c r}$ and the critical extension stress, $\sigma_{p c r}$ developed at the pipe wall is given by:

$p_{c r}=\sigma_{p c r}\left(\frac{2 d}{D+d}\right)$

The relationship between values of $\sigma_{p c r}$ and $\sigma_{w c r}$ required by standards of pressure rigid pipe standards is commonly given by:

$\sigma_{w c r} \approx 2 \sigma_{p c r}$

As an example, the standard for pressure AC pipes IS333 (see Appendix) requires the minimum value of $\sigma_{p c r}=22$ $\mathrm{MPa}$, and the minimum value of $\sigma_{w c r}=44 \mathrm{MPa}$. However, experiments carried out by Bar-Shlomo [14] have shown that AC pipes produced in Israel have been of significantly better material qualities, namely $\sigma_{w c r} \approx 75 \mathrm{MPa}$ and $\sigma_{p c r} \approx 30$ $\mathrm{MPa}$.

For calculating the required strength of force mains, Schlick's formula [15] is commonly applied by various standards, like AWWA C-403 (see Appendix). According to this formula, the failure of the rigid pipe subject to external load combined with internal pressure is given by this expression:

$\left(\frac{W}{W_{c r}}\right)^{2}+\left(\frac{p}{p_{c r}}\right)=1$ 
Applying this formula, standards for selecting force mains like, AWWA C-403 (see Appendix) and texts [9] provide criteria for safe design and proper service of the pipe subject to external load combined with internal pressure. According to these criteria the safe design of such pipes, namely force mains, should comply with the following relationships:

$$
\frac{W}{W_{c r}}<\sqrt{1-\left(\frac{p}{p_{c r}}\right)}
$$

and

$$
\frac{p}{p_{c r}}<1-\left(\frac{W}{W_{c r}}\right)^{2}
$$

In this study we suggest considering Equation (17) as representing the "Pipe Failure" curve, in which values of $p / p_{c r}$ are given as a function of $W / W_{c r}$ values. We also extend Schlick's formula to obtain expressions for "Service Curves", by properly introducing safety factors into Equation (17). Each service curve is associated with a particular value of the pipe construction safety factor. Various standards, like IS-333 (see Appendix) specify the safety factor $S_{f w}$ that represents the minimum allowed ratio of $W_{c r}$ to $W$ provided the pipe is only subject to external load. Such standards also specify the minimum ratio of $p_{c r}$ to $p$ provided the pipe is only subject to internal pressure. In some cases, standards like BS-486 (see Appendix) provide several safety factors referring to field service and testing the pipeline after completing its installation. However, after reviewing quite a few pressure rigid pipe standards we may conclude:

$S_{f p} \geq S_{f w}$

Or

$S_{f p}=R_{f} S_{f w}$ where $R_{f} \geq 1$

Here $R_{f}$ is the ratio of $S_{f p}$ to $S_{f w}$.

Introducing the safety factors for external load and internal pressure into Equation (17) we obtain the following formula of safe pipe service:

$\left(\frac{S_{f w} W}{W_{c r}}\right)^{2}+\left(\frac{S_{f p} p}{p_{c r}}\right)=1$

This formula may represent safe service curves of the force main, namely curves of $p / p_{c r}$ versus $W / W_{c r}$, in which values of safety factors $S_{f w}$ and $S_{f p}$ are taken into account.

We introduce Equations (13) and (15) into Equation (21) to obtain:

$$
\left[\frac{W S_{f v} n(3 D+5 d)}{\sigma_{w c r} d^{2}}\right]^{2}+\frac{p S_{f p}(D+d)}{2 \sigma_{p c r} d}=1
$$

Or

$$
p=\frac{2 \sigma_{p c r} d}{S_{f p}(D+d)}\left\{1-\left[\frac{W S_{f w} n(3 D+5 d)}{\sigma_{w c r} d^{2}}\right]^{2}\right\}
$$

Equation (22) represents pipe service formulas (or curves), which depend on measurable quantities and re- quired safety factors. Usually, the value of $D$ is determined according to the operating hydraulic conditions (discharge and range of acceptable flow velocities) of the force main; values of $W$ and $p$ are determined by the service field conditions of the pipe; values of $\sigma_{w c r}$ and $\sigma_{p c r}$ are known according to the pipe material properties; values of the safety factors $S_{f w}$ and $S_{f p}$ are given by the specific standard applied to selecting the pipe. Therefore, Equation (22a) is a nonlinear expression useful for directly calculating the required thickness of the rigid pressure pipe wall. As an example we have applied Equation (22b) to depict Fig. (4), which includes several curves of the proper pipe service. These service curves provide the relationships between $p$ and $W$ for force mains made of AC with $D=1,250 \mathrm{~mm}$ and various wall thickness values, complying with IS-333 (see Appendix), namely, $\sigma_{w c r}=44 \mathrm{MPa}$, and $\sigma_{p c r}=22 \mathrm{MPa}$. Fig. (4) also shows service curves of AC pressure pipes, whose material strength is represented by the experimental results of Bar-Shlomo [14] namely $\sigma_{w c r} \approx 75 \mathrm{MPa}$, and $\sigma_{p c r} \approx 30 \mathrm{MPa}$.

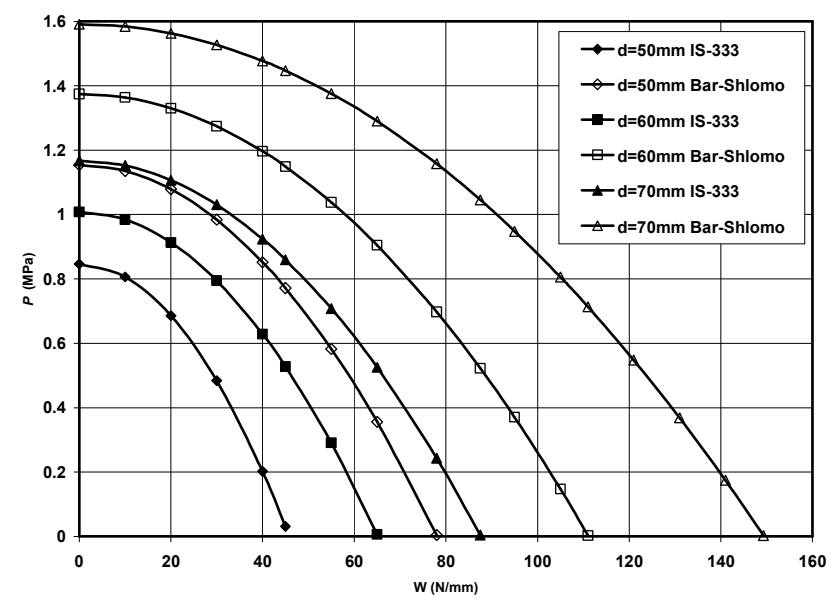

Fig. (4). Service curves representing values of $p$ versus $W$ for AC pipes of $D=1,250 \mathrm{~mm}$, complying with IS-333 ( $\sigma_{w c r}=44 \mathrm{MPa}$; $\sigma_{p c r}=22 \mathrm{MPa}$ ) and those represented by the experimental results of Bar-Shlomo [14], namely $\sigma_{w c r}=75 \mathrm{MPa}$ and $\sigma_{p c r}=30 \mathrm{MPa}$; with safety factors $S_{f p}=S_{f w}=2$ for various values of the pipe wall thickness ( $d$-values).

\section{THE EFFECT OF THE GROOVE AT THE PIPE INVERT}

According to Fig. (2), the cross section of the groove developed at the force main invert can be approximated as a trapezoidal or a semi-circle. As shown by Lindeburg [16] and other manuals and texts, whenever there is a discontinuity or non-uniformity in an object subject to extension stresses, it is convenient to consider a model of stress streamlines within the object. With regard to the force main with invert subject to bedload erosion, such a stress model shows stress concentration within the groove region. Therefore, the appearance of a fracture is most probable at the groove, where the wall material is subject to particularly high stresses leading to separation of the material lamina due to the changing extension stress direction.

The groove developed at the AC force main invert in Tel-Aviv area had a maximum depth of $20 \mathrm{~mm}$ and maxi- 
mum width of $40 \mathrm{~mm}$. We may apply Peterson's stress concentration factors [17] to calculate the effect of the semicircular groove on stress concentration without considering the distribution of stresses at the invert groove. However, we have applied Peterson's stress concentration factors to check our numerical simulation results with the ANSYS code. On the other hand, we have extensively applied the ANSYS code to carrying out numerical simulations that follow the effect of the groove on stress magnitudes and stress distributions induced by the external load combined with internal pressure, as described in following paragraphs.

We have hypothesized that although stress distribution at the invert groove is significantly nonuniform Equations (17) and (21) are also applicable to rigid pipes with grooves at their invert. We may consider that such an assumption is on the safe side, as the pipe wall better resists nonuniform stress distribution (which is resulting from external load) than uniform stress distribution (which results from internal pressure) However, values of $W_{c r}$ and $p_{c r}$ are reduced due to the presence of the groove. Further, we made calculations with ANSYS code to evaluate the effect of the groove on the pipe structural strength and stress distribution at the pipe wall. Fig. (5) shows an example of the numerical results of stress distribution at the pipe invert without and with a groove (which is $20 \mathrm{~mm}$ deep and $40 \mathrm{~mm}$ wide). The pipe diameter is $1,250 \mathrm{~mm}$ and the wall thickness is $70 \mathrm{~mm}$. This pipe is only subject to an external load of $60 \mathrm{~N} / \mathrm{mm}$. Fig. (5a) shows that maximum extension stress developed at the pipe invert without a groove is around $15.4 \mathrm{MPa}$, which is identical with the value of $\sigma_{\mathrm{w}}$ calculated by using Equation (13). For the same pipe with a groove subject to only the external load of $60 \mathrm{~N} / \mathrm{mm}$ the maximum extension stress is $38.1 \mathrm{MPa}$. The extension stress developed at the pipe invert is proportional to the external load, $W$. Therefore, for an AC pipe with diameter $1,250 \mathrm{~mm}$ and wall thickness $70 \mathrm{~mm}$, which complies with the minimum requirements of the standard IS-333 (see Appendix), namely $\sigma_{w c r}=44 \mathrm{MPa}$, the critical external load without a groove is $W_{c r}=175 \mathrm{~N} / \mathrm{mm}$. The presence of the groove at the invert of such a pipe reduces its critical external load to $W_{c r}=69 \mathrm{~N} / \mathrm{mm}$. For the same pipe with the critical extension value reported by Bar-Shlomo [14], namely $\sigma_{w c r}=75 \mathrm{MPa}$, the critical external load decreases from $W_{c r}=292 \mathrm{~N} / \mathrm{mm}$ for the case of no groove at the pipe invert to $W_{c r}=118 \mathrm{~N} / \mathrm{mm}$ due to the presence of the groove at the pipe invert.

Fig. (6) shows the numerical results of stress distribution at the pipe wall without and with a groove at its invert (which is $20 \mathrm{~mm}$ deep and $40 \mathrm{~mm}$ wide). The pipe diameter is $1,250 \mathrm{~mm}$ and its wall thickness is $70 \mathrm{~mm}$. In this case the pipe is subject to only an internal pressure of $0.5 \mathrm{MPa}$, namely 5 bar. Fig. (6a) shows that maximum extension stress developed at the pipe wall without a groove is around $\sigma_{p}=4.7 \mathrm{MPa}$. This result is identical with calculating the value of $\sigma_{p}$ by applying Equation (15). According to Fig. (6b), the presence of the groove at the pipe invert increases the extension stress at the pipe invert to around $\sigma_{p}=20.1$ $\mathrm{MPa}$. Again, as the extension stress is proportional to the value of the internal pressure, for an AC pipe with diameter $1,250 \mathrm{~mm}$ and wall thickness $70 \mathrm{~mm}$, which complies with the minimum requirements of the standard IS-333 (see Appendix), namely $\sigma_{p c r}=22 \mathrm{MPa}$, the critical internal pressure without a groove is $p_{c r}=2.34 \mathrm{MPa}$, namely $p_{c r}=23.4 \mathrm{bar}$. The presence of the groove at the invert of such a pipe reduces its critical internal pressure to $p_{c r}=0.55 \mathrm{MPa}$, namely $p_{c r}=5.5$ bar. For the same pipe with the critical extension stress value reported by Bar-Shlomo [14], namely $\sigma_{p c r}=30$ $\mathrm{MPa}$, the critical internal pressure decreases from $p_{c r}=3.2$ $\mathrm{MPa}$ (namely, 32 bar) for the case of no groove at the pipe wall to $p_{c r}=0.75 \mathrm{MPa}$, namely $7.5 \mathrm{bar}$, due to the presence of the groove at the pipe invert.

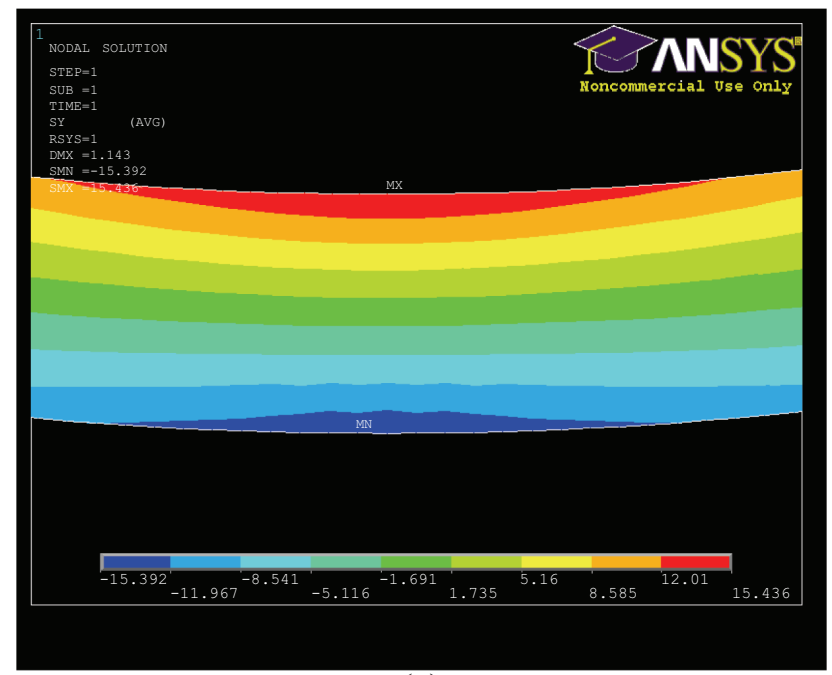

(a)

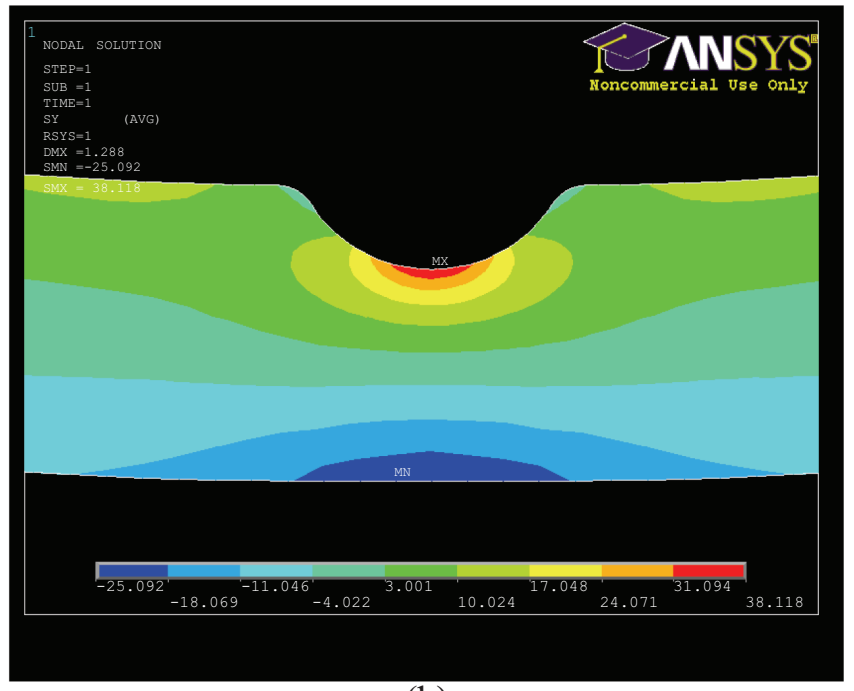

(b)

Fig. (5). Numerical results of stress distribution at the invert of a pipe of diameter $1,250 \mathrm{~mm}$ and wall thickness $70 \mathrm{~mm}$ subject to external load of $60 \mathrm{~N} / \mathrm{mm}$ (stresses are measured in MPa): a) Pipe without a groove, b) Pipe with a groove $20 \mathrm{~mm}$ deep and $40 \mathrm{~mm}$ wide.

\section{THE COLLAPSE OF THE FORCE MAIN IN TEL-AVIV AREA}

As indicated by the introduction section, the collapse of the AC force main in Tel-Aviv area has led to the motivation of carrying out this study. Therefore, in this section we apply the approach and basic information represented in the pre- 
ceding sections to analyze the possible connection between the collapse of the force main in Tel-Aviv area and the groove developed at its invert.

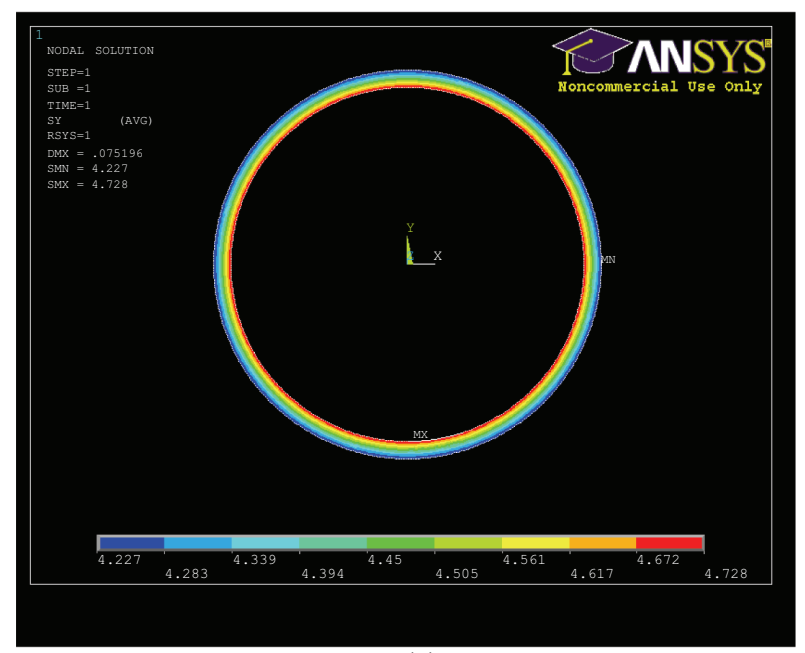

(a)

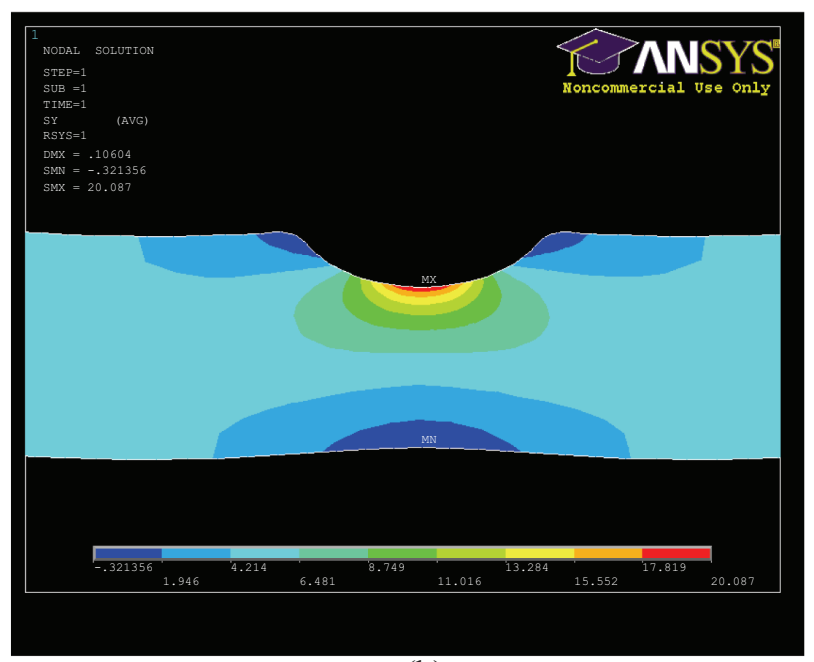

(b)

Fig. (6). Numerical results of stress distribution at the wall of a pipe of diameter $1,250 \mathrm{~mm}$ and wall thickness $70 \mathrm{~mm}$ subject to internal pressure of $0.5 \mathrm{MPa}$, namely 5 bar (stresses are measured in $\mathrm{MPa}$ ): a) Stress distribution at the pipe wall without a groove, b) Stress distribution at the pipe invert with a groove $20 \mathrm{~mm}$ deep and $40 \mathrm{~mm}$ wide.

Fig. (7) provides a schematic description of the trench in which two force mains were laid in 1973. One of them collapsed on January 28, 2003 after 30 years of good service. No effect or damage of any type including corrosion has been observed at the inner wall of the pipe, except for the groove developed at its invert. The two force mains were laid in a trench with sizes schematically shown in Fig. (7). They were covered with a backfill layer of sand and gravel of thickness $H=300 \mathrm{~cm}$. In such a case the effect of live load on the pipe is much smaller than the external load applied by the backfill and can be neglected. For a system of two force mains laid in a trench, as shown in Fig. (7), the effective trench width applied to each force main, $B_{d}$ is given by [11]:

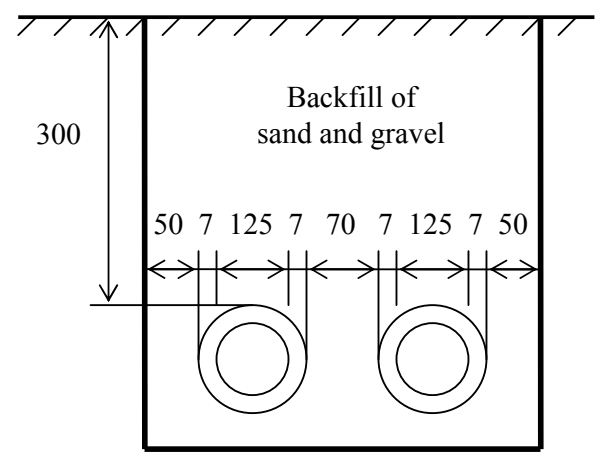

Fig. (7). Schematic description of the trench with two pressure pipes of the case history of force main collapsed in Tel-Aviv area (sizes are given in $\mathrm{cm}$ ).

$$
B_{d}=B_{c}+2 w=139+2 \times 50=239 \mathrm{~cm}
$$

where $B_{c}$ is the external diameter of the pipe and $w$ is the distance of the pipe external wall from the wall of the trench. The backfill load, $W_{d}$ applied to the force main is calculated by applying the following Iowa formula (e.g., [11]):

$$
W_{d}=C_{d} \gamma B_{d}^{2}
$$

where $\gamma$ is the specific weight of the backfill and $C_{d}$ is the backfill external load coefficient, whose value is given by:

$$
C_{d}=\frac{1-\exp \left(-2 K \mu^{\prime} H / B_{d}\right)}{2 K \mu^{\prime}}
$$

where $K$ is Rankin coefficient and $\mu^{\prime}$ is the friction coefficient between the backfill and the trench wall. In cases of backfill made of sand and gravel, the value of $K \mu^{\prime}$ is around 0.165 . By introducing this quantity and values of $H$ and $B_{d}$ into Equation (25) we get $C_{d}=1.028$. Considering the specific weight of the backfill is $\gamma=19,620 \mathrm{~N} / \mathrm{m}^{3}$ (namely density of $2,000 \mathrm{~kg} / \mathrm{m}^{3}$ ) and introducing this quantity with values of $C_{d}$ and $B_{d}$ into Equation (24) we get $W_{d}=115,209$ $\mathrm{N} / \mathrm{m}$. To this value we should add the weight of the pipe and the water flowing through the conduit to get the total external load applied to the conduit subject to field service, namely $W_{f}=131,179 \mathrm{~N} / \mathrm{m}=131.2 \mathrm{~N} / \mathrm{mm}$. Considering bedding of class B (e.g., [11]), the bedding factor for the pipeline is $B_{f}=1.9$. Now we convert the external load of field conditions into external load represented by the three-edgeload crushing test, namely:

$$
W=\frac{W_{f}}{B_{f}}=\frac{131.2}{1.9}=69 \mathrm{kN} / \mathrm{m}=69 \mathrm{~N} / \mathrm{mm}
$$

In addition to the external load given by Equation (26) the force main has also been subject to an internal pressure of 3.7 bar, namely $0.37 \mathrm{MPa}$. The external load combined with internal pressure should be considered for evaluating the possible cause of the force main collapse in Tel-Aviv area.

In order to evaluate the safety factors of operating the rigid pressure pipe with a groove developed at its invert, we introduce Equation (20b) into Equation (21), to obtain: 
$S_{f w}^{2}\left(\frac{W}{W_{c r}}\right)^{2}+S_{f w}\left(\frac{p R_{f}}{p_{c r}}\right)-1=0$

Solving this second order equation for $S_{f w}$ and applying Equation (20b) yield values of $S_{f w}$ and $S_{f p}$, respectively:

$$
S_{f w}=\frac{-\left(\frac{p R_{f}}{p_{c r}}\right)+\sqrt{\left(\frac{p R_{f}}{p_{c r}}\right)^{2}+4\left(\frac{W}{W_{c r}}\right)^{2}}}{2\left(\frac{W}{W_{c r}}\right)^{2}}
$$

$S_{f p}=R_{f} S_{f w}$

We introduce values of $W=69 \mathrm{~N} / \mathrm{mm}$ and $p=0.37 \mathrm{MPa}$, which have been applied to the AC pipe in Tel-Aviv area (namely, an AC pipe with $D=1,250 \mathrm{~mm}$, and $d=70 \mathrm{~mm}$ with an invert groove $20 \mathrm{~mm}$ deep and $40 \mathrm{~mm}$ wide). As shown in the preceding section, for such a pipe complying with the minimum extension stresses required by the standard IS-333 (see Appendix), namely $\sigma_{w c r}=44 \mathrm{MPa}$ and $\sigma_{p c r}$ $=22 \mathrm{MPa}$, critical values of the external load and the internal pressure are, $W_{c r}=69 \mathrm{~N} / \mathrm{mm}$ and $p_{c r}=0.55 \mathrm{MPa}$, respectively. For such a pipe with properties measured by BarShlomo [14], namely $\sigma_{w c r}=75 \mathrm{MPa}$ and $\sigma_{p c r}=30 \mathrm{MPa}$, critical values of the external load and the internal pressure are, $W_{c r}=118 \mathrm{~N} / \mathrm{mm}$ and $p_{c r}=0.75 \mathrm{MPa}$, respectively. We apply the requirement of the standard IS-333 (see Appendix), which states $R_{f}=1$ and introduce all relevant quantities into Equations (27) and (28) to obtain $S_{f w}=S_{f p}=0.72$ for the AC pipe complying with the minimum requirements of IS333. This result indicates that the groove at the invert of such a pipe could lead to its collapse. For the AC pipe with properties described by Bar-Shlomo [14] we obtain $S_{f w}=S_{f p}$ $=1.13$. This value is smaller than needed for proper design of the pipeline, but indicates that the significant strength reduction of the pipe due to the presence of the groove probably could not be the only cause of the pipe collapse in Tel-Aviv area, provided its properties are represented by the experiments of Bar-Shlomo [14]. As production of AC pipes stopped in Israel during the 90's, in 2003, after the event of the pressure main collapse in Tel-Aviv area, no facilities were available for proper measuring values of $\sigma_{w c r}$ and $\sigma_{p c r}$ of AC pipes. Therefore, using some alternative methods of testing the AC pressure pipes with concrete pipe testing facilities and various additional tests have indicated that properties of the AC pressure main in Tel-Aviv area were similar to those measured by Bar-Shlomo [14]. Therefore, in addition to the groove developed at the pipe invert possibly some other reasons have been involved in the force main collapse. Collecting field data has implied that also some damage at the pipe foundation due to groundwater upward flow has been involved in the force main collapse.

Fig. (8) incorporates failure curves of AC pipes of 1,250 $\mathrm{mm}$ diameter and wall thickness $70 \mathrm{~mm}$, which comply with the standard IS-333 (see Appendix), and those represented by the strength found by Bar-Shlomo [14], with and without a groove (which is $20 \mathrm{~mm}$ deep and $40 \mathrm{~mm}$ wide). It also shows the point of work of the force main in Tel-Aviv area. This figure visualizes the possible collapse of an AC pipe provided it has been manufactured according to the mini- mum strength of material required by the standard IS-333 (see Appendix); as the point of work of the AC pipe is located above the failure curve of such a pipe. On the other hand the point of work of the AC pipe is located below the failure curve of the AC pipe whose properties have been measured by Bar-Shlomo [14], indicating that such a pipe may still resist the external load combined with internal pressure, as took place in Tel-Aviv area.

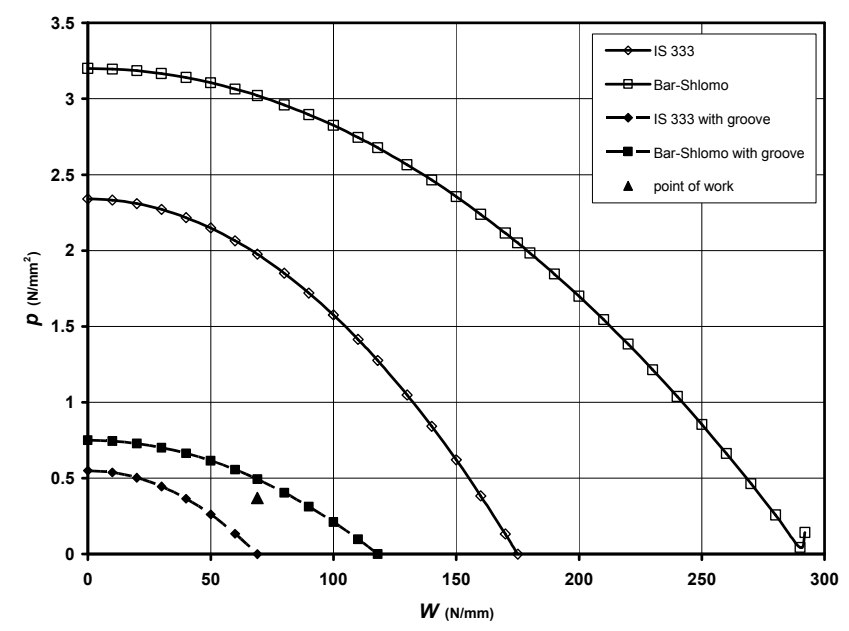

Fig. (8). Failure curves of AC pipes $(D=1,250 \mathrm{~mm} ; d=70 \mathrm{~mm})$ complying with IS-333 $\left(\sigma_{w c r}=44 \mathrm{MPa}, \sigma_{p c r}=22 \mathrm{MPa}\right)$ and those obtained by applying results of Bar-Shlomo [14] $\left(\sigma_{w c r}=75 \mathrm{MPa}\right.$, $\left.\sigma_{p c r}=30 \mathrm{MPa}\right)$ with and without grooves $(20 \mathrm{~mm}$ deep and $40 \mathrm{~mm}$ wide), as well as the point of work of the force main in Tel-Aviv area.

\section{DISCUSSION}

Experimental evidence and requirements of pipe manufacturing standards indicate the critical extension stress leading to pipe collapse due to internal pressure is significantly smaller than the critical extension stress originating from external loading of the pipe. The internal pressure leads to almost uniform extension stress distribution at the pipe wall, whereas the maximum value of the bending moment attributed to external load crushing leads to a triangular stress distribution at the pipe wall invert changing from maximum compression at the wall outer side to maximum extension stress at the wall inner side. Therefore, we may conclude that the pipe wall collapse takes place for values of extension stresses uniformly distributed smaller than those attributed to stresses non-uniformly distributed. As shown in Fig. (6), the presence of the groove at the pipe invert leads to stress concentration at that region and increases the value of the maximum extension stress attributed to the internal pressure. However, this figure indicates the stresses at the groove region are significantly nonuniformly distributed. Therefore, it is very much possible that assuming $\sigma_{p c r}$ for a pipe without groove identical with $\sigma_{p c r}$ for a pipe with a groove at its invert provides some safety factor to our calculations. Further, hypothesizing and using values of $\sigma_{w c r}$ and $\sigma_{p c r}$ identical for pipes with and without grooves in Schlick's formula [15] is possibly providing some safety factor to the calculations. 


\section{CONCLUDING REMARKS}

The information represented in this article indicates the resistance of the pipe wall material to abrasion may be an important factor for the life service of collection systems. Many studies refer to pipe abrasion due to the presence of high concentrations of hard solid particles transported with the water flowing through the conduit. High concentrations of such solid particles are usually present in flows through culverts and drainage systems. At high flow velocities these solids may be transported as suspended load and/or as bedload causing abrasion to the entire inner surface of the pipe wall, and mainly at the pipe invert. However, this study concerns cases of pipe wall abrasion caused by very low concentrations of hard solid particles. Such cases are typical of some CSS and sewerage systems (including flows in force mains as well as in gravitational sewerage) that are occasionally fed by surface run-off and other sources of hard solid particles. Continuous operation of such sewerage systems may be incorporated with the risk of gradual developing narrow and deep groove at the pipe invert. Such a groove may significantly reduce the pipe structural strength, due to stress concentration at the groove region. In this study we hypothesize that Schlick's formula [15] can be extended for calculating the durability of force mains with invert grooves. Such calculations may indicate the possible cause of force main collapses in specific case histories. We also consider that our hypothesis incorporates some safety factors for predicting the possible force main collapse, as the presence of the groove leads to a new type of nonuniform stress distribution at the pipe invert. This study specifically addresses the possible collapse of force mains, which may lead to significant environmental damages. However, the phenomenon of groove development may take place in all types of collection systems. The common approach for collection system survey and monitoring is usually applying closed circuit TV (CCTV) testing. Such testing procedure may provide very good information about the pipe wall condition (including root penetration and corrosion) above the surface of the wastewater flowing in the conduit. On the other hand, CC-TV monitoring does not provide information about the inner surface of the pipe wall below the flowing wastewater surface, where the groove may develop at the pipe invert and gradually reduce the structural strength of the conduit.

\section{ACKNOWLEDGEMENTS}

The study reported by this article has been carried out at Technion - Israel Institute of Technology, Israel, where it has been supported by a research grant of The Grand Family Water Research Institute (GWRI). The study has also been supported by RWTH Aachen University via the Institute of Hydraulic Engineering and Water Resources Management. The authors thank Eng. Gideon Zac, formerly General Manager of Dan area Communities Consortium for providing the basic field data used for this study. We are grateful to Prof. Robert Levy of Technion for his help and guidance with using the ANSYS code for the numerical simulations required by this study. The authors appreciate very much the information and photos concerning issues of this study given by Eng. Paul Wilting, Senior Project Engineer, Greater Vancouver Regional District. Helpful comments and discussions with Prof. Thomas O'Rourke of Cornell University are deeply appreciated.

\section{NOMENCLATURE}

$\begin{array}{ll}B_{c} & =\text { External pipe diameter, }[L] \\ B_{d} & =\text { Effective trench width, }[L] \\ B_{f} & =\text { Bedding factor } \\ C_{d} & =\text { Backfill external load coefficient } \\ C_{s} & =\text { Average concentration of hard solid particles } \\ & =\text { in the wastewater, }\left[M L^{-3}\right] \\ D & =\text { Inner diameter of the pipe, }[L] \\ d & =\text { Thickness of the pipe wall, }[L] \\ K & =\text { Rankin coefficient } \\ k & =\text { Coefficient originating from the pipe curva- } \\ M & =\text { Bending moment per unit length, }\left[M L T^{2}\right] \\ M_{b} & =\begin{array}{l}\text { Bending moment per unit length at the pipe } \\ \text { bottom, }\left[M L T^{2}\right]\end{array} \\ M_{c r} & =\begin{array}{l}\text { Critical value of the bending moment per unit } \\ \text { length, }\left[M L T^{2}\right]\end{array} \\ M_{\text {max }} & =\begin{array}{l}\text { Maximum value of the bending moment per } \\ \text { unit length, }\left[M L T^{-2}\right]\end{array}\end{array}$

$M_{t}=$ Bending moment per unit length at the pipe top, $\left[M L T^{2}\right]$

$M_{\theta}=$ Bending moment per unit length at an angle $\theta$ with regard to the pipe bottom, $\left[M L T^{2}\right]$

$M_{90^{\circ}}=$ Bending moment per unit length at an angle $\theta$ $=90^{\circ},\left[M L T^{2}\right]$

$m_{s b r}=$ Total mass per day of hard solid particles accumulated at the biological reactor, $\left[M T^{1}\right]$

$m_{\text {sur }}=$ Total mass per day of hard solid particles accumulated upstream of the biological reactor, $\left[M T^{-1}\right]$

$n=$ Coefficient (for pipe diameter larger than 100 $\mathrm{mm} n=0.3$ )

$p \quad=\quad$ Internal pressure, $\left[M T^{2} L^{-1}\right]$

$p_{c r}=$ Critical internal pressure, $\left[M T^{2} L^{-1}\right]$

$Q_{d}=$ Volume of wastewater per day arriving at the biological reactors, $\left[L^{3} T^{1}\right]$

$R=$ Average radius of the rigid pipe, $[L]$

$R_{f} \quad=\quad$ Ratio of $S_{f p}$ to $S_{f w}$

$S_{f p}=$ Safety factor applied to the pipe internal pressure

$S_{f w}=$ Safety factor applied to the pipe external load

$W \quad=\quad$ Two-edge (or three-edge) external testing load per unit length, $\left[M T^{2}\right]$ 
$W_{c r} \quad=\quad$ Critical value of $W,\left[M T^{2}\right]$

$W_{d}=$ Backfill external load per unit length, $\left[M T^{2}\right]$

$W_{f} \quad=\quad$ Field external load per unit length, $\left[M T^{2}\right]$

$W_{f c r} \quad=\quad$ Critical value of $W_{f},\left[M T^{2}\right]$

$w \quad=\quad$ Distance between the external pipe wall and the trench wall, $[L]$

$Z=$ Modulus of the pipe wall per unit length, $\left[L^{2}\right]$

\section{GREEK SYMBOLS}

$\gamma=$ Specific weight of the backfill, $\left[M L^{-2} T^{2}\right]$

$\mu^{\prime} \quad=$ Coefficient of friction between the backfill and the trench wall $\theta=\quad$ Radial angle with regard to the pipe bottom

$\rho_{s}=$ Average density of the hard solid particles, $\left[M L^{-3}\right]$

$\sigma_{p} \quad=\quad$ Extension stress caused by the internal pressure, $\left[M T^{2} L^{-1}\right]$

$\sigma_{p c r}=$ Critical extension stress caused by the internal pressure, $\left[M T^{2} L^{-1}\right]$

$\sigma_{w}=$ Extension stress caused by the bending moment, $\left[M T^{2} L^{-1}\right]$

$\sigma_{w c r}=$ Critical extension stress caused by the bending moment, $\left[M T^{-2} L^{-1}\right]$

$\sigma_{w \max }=$ Maximum value of the extension stress caused by crushing, $\left[M T^{2} L^{-1}\right]$

\section{APPENDIX: STANDARDS CITED BY THIS STUDY}

\section{American National Standards Institute (ANSI)/ American Water Works Association (AWWA)}

ANSI/AWWA C-403-84. "The Selection of Asbestos-Cement Transmission and Feeder Main Pipe. Sizes 18 in. through 42 in. (450 mm through $1050 \mathrm{~mm}) "$

\section{American Society of Testing and Materials (ASTM)}

ASTM C-14M-99. "Standard Specification for Concrete Sewer, Storm Drain, and Culvert Pipe [metric]"

ASTM C-296. "Standard Specification for Asbestos-Cement Pressure Pipe"

ASTM C-418, Standard Test Method for Abrasion Resistance of Concrete by Sand Blasting"

ASTM C-500-98. "Standard Test Methods for Asbestos-Cement Pipe"

ASTM C-779. "Standard for Assessing the Abrasion Resistance of Horizontal Concrete Surface, Procedure A, Revolving Disk"; "Procedure B, Dressing Wheel"; "Procedure C, Ball Bearing"

ASTM C-875-98. "Standard Specification for Asbestos-Cement Conduit"

ASTM C-944. "Standard Test Method for Abrasion Resistance of Concrete or Mortar Surfaces by the Rotating Cutter Method"

\section{British Standards (BS)}

BS-486. "Asbestos-Cement Pressure Pipes"

\section{International Organization for Standardization (ISO)}

ISO-160. "Asbestos-Cement Pressure Pipes and Joints"

ISO-881. "Asbestos-Cement Pipes, Joints and Fittings for Sewerage and Drainage"

ISO-2785. "Directives for Selection of Asbestos-Cement Pipes Subject to External Loads with or without Internal Pressure"

\section{Israel Standard (IS)}

IS-27. "Concrete and Reinforced Concrete Circular Pipes"

IS-333. "Asbestos-Cement Pressure Pipes and Joints"

\section{REFERENCES}

[1] B.J. Pigg, "A Review of the Regulatory Facts Affecting Asbestos Cement Pipe," American Water Works Association Conference, ISBN: 0-89867-556-1, 1990.

[2] R.L. Virta. Worldwide Asbestos Supply and Consumption Trend from 1900 to 2000, USGS Open-File Report 03-83, 2003.

[3] Greater Vancouver Sewerage and Drainage District, Incident Report - Release of Wastewater through Overflows to Burrard Inlet, Report Prepared for Ministry of Environment, Lands and Parks Environmental Protection, September 2000.
[4] R.C. Edmunds, "Pipeline Design Lessons of Recent Prestressed Concrete Pressure Pipe Failures," American Water Works Association Conference, ISBN: 0-89867-592-8, 1991.

[5] M.T. Peabody, M.T. 1992. "Repair and Rehabilitation of Prestressed Concrete Pipe at the Central Arizona Project," American Water Works Association Conference, ISBN: 0-89867-651-7, 1992.

[6] P. Wilting, Records of Force Main Failure in Vancouver, Greater Vancouver Regional District (presently, "Metro Vancouver"), Personal Communication, 2004.

[7] L.H. Gabriel, A Study of Invert Wear of Ultra-Rib PVC Profile Pipes, California State University, Sacramento, CA, 1992. 
[8] J.J. Jarvenkyla and K.T. Haavisto, "The Abrasion Resistance of Sewers- Part 2," Pipes \& Pipelines International, NovemberDecember 1993, 38-40.

[9] O.C. Young and J.J. Trott, Buried Rigid Pipes - Structural Design of Pipelines, Elsevier, London, 1984.

[10] W.C. Young and R.G. Budynas, Roark's Formulas for Stress and Strain, $7^{\text {th }}$ ed. McGraw-Hill, New York, 2002.

[11] American Concrete Pipe Association, Concrete Pipe Handbook, ISBN 0-960-38681-6, 1998.

[12] American Water Works Association, Concrete Pressure Pipe AWWA M9, $2^{\text {nd }}$ ed., ISBN: 0898670675, 1995.
[13] L.C. Urquhart, Ed. Civil Engineering Handbook, McGraw-Hill, NY, 1959.

[14] S. Bar-Shlomo, Durability of Asbestos-Cement Pipes, M.Sc. Thesis, Faculty of Civil Engineering, Technion, Haifa, Israel, 1964

[15] W.J. Schlick, Supporting Strength of Cast-Iron Pipe for Water Service, Bulletin No.146, Iova State College, 1940.

[16] M.R. Lindeburg, Engineering in Training Reference Manual, $8^{\text {th }}$ ed, Professional Publications, Belmont, CA, 1998.

[17] W.D. Pilkey, Petersons`s Stress Concentration Factors, $2^{\text {nd }}$ ed John-Wiley \& Sons, NY, 1997.

Received: August 15, 2009

Revised: August 23, 2010

Accepted: September 01, 2010

(C) Rubin et al.; Licensee Bentham Open.

This is an open access article licensed under the terms of the Creative Commons Attribution Non-Commercial License

(http://creativecommons.org/licenses/_by-nc/3.0/) which permits unrestricted, non-commercial use, distribution and reproduction in any medium, provided the work is properly cited. 